https://helda.helsinki.fi

\title{
Fluency in English as a lingua franca interaction
}

\section{Hynninen, Niina}

Multilingual matters

2019

Hynninen, N 2019 , Fluency in English as a lingua franca interaction . in P Lintunen , M

Mutta \& P Peltonen (eds), Fluency in L2 learning and use. Multilingual matters, Bristol, pp. $81-95$.

http://hdl.handle.net/10138/340841

unspecified

acceptedVersion

Downloaded from Helda, University of Helsinki institutional repository.

This is an electronic reprint of the original article.

This reprint may differ from the original in pagination and typographic detail.

Please cite the original version. 


\section{Fluency in English as a lingua franca interaction}

Niina Hynninen, University of Helsinki

\section{Introduction}

Research on English as a lingua franca (ELF) is concerned with communication in English in settings where at least one of the speakers uses English as a second language (L2). ELF is sometimes taken to exclude native speakers of English and to apply only to speakers for whom English is not a first language (L1) (e.g., Firth, 1996; House, 1999), but the definition adopted here is one that accepts native speakers as part of the mix (e.g., Jenkins, 2007; Mauranen, 2012; Seidlhofer, 2004, 2011). Hence, I define ELF as "a contact language between speakers or speaker groups when at least one of them uses it as a second language" (Mauranen, 2017: 8). A key term in understanding the definition is "L2 use" (Mauranen, 2012). In ELF research, ELF communication is treated as perfectly normal language use, which takes place in settings where the speakers' primary goal is not to "learn more English", but rather to communicate with their interlocutors (e.g., Ranta, 2009). An L2 speaker of English in an ELF setting is thus a user, rather than a learner, of English. ELF research explores communication between these L2 users of English, along with any L1 speakers of different varieties of English taking part in the interactions.

In addition, contrary to Second Language Acquisition (SLA) research, where the unit of analysis tends to be the individual L2 learner, the focus of much ELF research has been "on a level above the individual" (Ranta, 2009: 88), and on wider patterns in the ways L2 users of English interact and make use of their linguistic resources in practice. The data are typically naturally-occurring, rather than elicited samples. For instance, much research on ELF has explored spoken ELF interaction, and what speakers do to achieve mutual understanding in such interactions. While fluency has typically not been the main focus of ELF studies, much ELF research has duly been concerned with issues related to the smoothness, ease or effortlessness of communicating in ELF settings - all attributes typically associated with 
fluency. Particularly the focus of ELF research on communication, rather than on individuals, also raises a number of questions related to the concept of fluency and how fluency could be approached in studying L2 learning. This chapter reviews existing literature on ELF from the perspective of fluency and seeks connections between ELF and L2 fluency research. The chapter ends with a discussion of the implications of ELF research for studying L2 fluency.

\section{How fluency has been approached in ELF research}

Few studies have explicitly approached fluency in ELF. Hüttner's (2009) small-scale study on perceived fluency is one of the few where the concept has been defined and discussed in the light of ELF research. I start by presenting Hüttner's (2009) study because her suggestion to approach fluency as a descriptor of interactions rather than of individual speakers highlights the interactional focus of ELF research in general and provides a good starting point for our discussion of the implications of ELF research for studying L2 fluency.

Hüttner (2009: 275) proposes "a dialogic conceptualization of fluency, focusing on interactivity as a crucial characteristic of it, and fluency as an enactment of a speaker's language competence adjustable to contextual conditions". In this conceptualisation, fluency is approached as an interactional, dialogic phenomenon where the key focus is on interaction and on fitting speech into context. Hüttner's (2009) proposition of fluency as an interactional phenomenon is supported by her analysis of two rated samples of ELF interactions. Interestingly, the raters described such ELF interactions as the most fluent where all participants contributed to the discussion and were involved in developing a coherent dialogue. In line with more interactionally oriented L2 fluency studies (e.g., McCarthy, 2010), the active involvement of participants in co-constructing the interaction thus seems to contribute to how fluent an interaction is perceived to be (Hüttner, 2009). One rater also commented that individual fluency levels could not be identified in one of the examples, which, Hüttner (2009) suggests, indicates that fluency could be viewed as a descriptor of interactions rather than of individual speakers.

While Hüttner's (2009) study is limited in its scope, her proposal is important in drawing attention to fluency not only as a characteristic of an individual speaker's production, but also and more importantly as a characteristic of the interaction the speaker is taking part in. This approach emphasises that speakers may appear more or less fluent depending on the person they are talking to or the situation in which they are interacting (e.g., Sato, 2014), which highlights the importance of considering speech in the interactional context in which it 
occurs (see also Bavelas et al., 2000). Hüttner's (2009) proposition can thus be seen to have important implications for evaluating speaker performance (see below).

Another study which focuses on fluency in ELF is by Prodromou (2008). This booklength study links fluency to idiomaticity, which seems to be associated with the use of prefabricated language or formulaic sequences (cf., Wray, 2002). Prodromou (2008) observes that English native language (ENL) prefabrications enhance fluency in ELF interaction, but that they can also cause problems for intelligibility. These findings are in line with other ELF studies that have explored the use of ENL idioms in ELF interaction and which, importantly, also consider how new idioms may be created (e.g., Pitzl, 2012; Seidlhofer \& Widdowson, 2009). Despite this attention to prefabrications, however, Prodromou's (2008) description of fluency takes pragmatic and socio-cultural perspectives into account (see McCarthy, 2010). Similarly to Hüttner (2009), he leans towards a more interactional understanding of fluency, even though he does not go quite as far as proposing fluency as a characteristic of interaction; rather, Prodromou (2008: 69) describes fluency as an "integrated ability to maintain smooth continuity in ongoing talk with pragmatic appropriateness of utterances". While this definition seems to emphasise the individual speaker, it also sees this speaker as taking part in interactions.

Taken together, Hüttner's (2009) and Prodromou's (2008) work implies that L2 fluency research that explores interactional oral fluency (e.g., Peltonen, 2017; Sato, 2014) is the most relevant from an ELF perspective. In such L2 fluency research, features typically associated with the (dis)fluency of an individual speaker's production (e.g., pausing and repair) are reexamined in terms of their role in the interaction where the individual participates. To explain this connection between ELF research and interactional fluency studies in more detail, I now turn to ELF studies that have not focused on fluency as such but that can be reinterpreted in light of fluency research. I have structured the discussion around Segalowitz's (2010) three dimensions of fluency and thus examine ELF research findings in relation to (a) cognitive fluency, which refers to the speed and efficiency of speech production processing, (b) utterance fluency, which, following Skehan's (2003, 2009; Tavakoli \& Skehan, 2005) classification, typically covers speed, pausing and repair, and (c) perceived fluency, or the listener's fluency evaluations. At the same time, I seek connections to studies that adopt a more interactional perspective on fluency (e.g., McCarthy, 2010; Peltonen, 2017; Sato, 2014), where fluency relates to smooth turn-taking, for instance, and may therefore be viewed as "a joint performance" (Sato, 2014: 88) between speakers. 


\section{Cognitive fluency in ELF}

Among the few studies within ELF research that can be seen to shed light on cognitive fluency in ELF, or the speed and efficiency of speech production processing (see e.g., Segalowitz, 2010), is Mauranen's (2012; see also 2007) corpus linguistic work on spoken academic ELF, and her focus on ELF phraseology in particular. Formulaic sequences, or chunks of language that are stored and accessed as whole units in one's memory, ease the cognitive load in language production (Wray, 2002). They have been found to make processing easier and more fluent, at least for L1 speakers (e.g., Pawley \& Syder, 1983; Wray, 2002). Typically, formulaic sequences consist of lexical words and grammatical elements, with fixed and variable parts. Mauranen (2012: 141-161) shows that L2 users of English in ELF interaction may use such conventionalised, phraseological units in ways that do not entirely match the target form, that is, they resort to approximate forms of the language. She first provides a number of examples from the ELFA corpus of English as a lingua franca in academic settings that resemble formulaic sequences. These examples include expressions such as take a closer look to the world, how to put the end on it and you said a lot of er good points. Later she discusses special features of ELF phraseology in more detail, including the multi-word unit some words about, for instance.

As can be seen, non-standard articles and prepositions as well as lexis that is untypical in ENL occur in the examples. However, as Mauranen puts it, all of these sequences are "recognisable as units of meaning in their contexts [...], these meanings match conventionalised phraseological units, because they seem to fall within an acceptable range of variability to be recognised and understood" (2012: 143-144). So, the examples provided above approximate to the following formulaic sequences: take a closer look at, put an end to, make a point and a few words about. The last example on the list was an interesting case of possible ELF-specific developments. In MICASE, a mainly ENL corpus of academic speaking (see Simpson et al., 2002), words about only occurred in the cluster of a few words about, whereas there was more variation in ELFA, with some words about as the most common pattern (Mauranen, 2012: 153-154).

Mauranen's argument is that these kinds of examples are "approximate versions of schematic wholes that to all intents look like being stored and processed as single wholes" (2012: 144). If this is true, it would mean that L2 users do not build every utterance from its smallest components (as suggested in Wray, 2002) but, similarly to L1 speakers, can rely on larger schematic units (see Vetchinnikova, 2014). In terms of cognitive fluency, this suggests 
that even though formulaic sequences in ELF may be malformed in relation to ENL, they may be accessed as prefabricated units and are thus quickly retrieved from memory, which can further be taken as evidence of normal processing and processing fluency.

What is more, Mauranen's (2012) findings illustrate that approximations rarely seemed to cause interactional disruption. Hence, it is possible that, similarly to speakers, listeners in ELF interaction may also rely on "fuzzy processing" (Mauranen, 2017), and may not notice that there would be anything "wrong" with the approximate forms used. In Mauranen's words,

an approximate form, for example, may not be harder to understand than a precise form, because a typical hearer is not very precisely attuned to Standard English (or any particular variety of English), but is likely to rely on fairly fuzzy processing in making sense of the interlocutor's speech.

(Mauranen, 2017: 18)

This engagement in fuzzy processing by both speakers and listeners in turn leads to acceptance of the approximations in interaction (Mauranen, 2012; 2017). In all, it could be argued that relying on this kind of fuzzy processing ensures the efficiency of speech production and reception in ELF.

\section{Utterance fluency in ELF}

Out of the three components typically associated with utterance fluency, that is, speed (e.g., speech rate), breakdown (different aspects of pausing), and repair (false starts, repetitions and rephrasings), the last one has received the most attention in ELF research. Studies conducted on achieving mutual understanding in ELF interaction are a case in point (e.g., Jenkins, 2000; Kaur, 2009; 2011; Mauranen, 2006; 2007; 2012; Pietikäinen, 2018). Without drawing explicit links to fluency research, ELF research has approached repair (particularly repetitions and rephrasings) as they occur in interaction. Studies have examined the kinds of features that cause repair, and the functions that repairs serve in the interaction. This approach is similar to some L2 fluency studies, where repairs have been approached from an interactional, problemsolving perspective (e.g., Peltonen, 2017). The perspective is a response to previous fluency research that shows that many of the speed and (especially silent) pause measures differentiate between fluent and non-fluent speakers (e.g., Bosker et al., 2013; Kormos \& Dénes, 2004), 
whereas it appears that repairs are not straightforward markers of disfluency (e.g., Götz, 2013; Riggenbach, 1991). With its interactional focus, ELF research on repairs can contribute to the further characterisation of fluency in interactional settings.

Jenkins's (2000) seminal study on the phonology of ELF stemmed from recognising which pronunciation features caused misunderstandings in ELF interaction, and were consequently a potential cause for repair. This led her to suggest a set of pronunciation features (known as the Lingua Franca Core) that may be more central to achieving mutual understanding in ELF contexts compared to other pronunciation features. To avoid repair work to resolve non- or misunderstandings caused by these other features, Jenkins (2000) concluded that speakers need both receptive and productive accommodation skills (see also Cogo \& Dewey, 2006). From an utterance fluency perspective, accommodation reduces the need for repair work; from a cognitive perspective, when speakers and listeners become more attuned to differences in pronunciation (and other) features, they become better at processing (see also Veivo \& Anckar in the present volume).

Although accommodation is readily observable in ELF interaction (e.g., Cogo \& Dewey, 2006; Hynninen, 2016), repair work is sometimes needed, and speakers have been found to draw on various means of preventing and resolving misunderstandings. These include the repetition of problematic items and (self-)rephrasing (see Pietikäinen, 2018 for a fuller list), which in L2 fluency research have often been treated as indicating disfluency (e.g., Skehan, 2009). What Mauranen (2007; 2012) suggests instead is that repetition and rephrasing in ELF may facilitate communication; that they may actually provide both speakers and listeners with "breathing spaces" (Mauranen, 2012: 230) that afford them the opportunity to prepare for what is going to be said next. For instance, her findings show that

repeats [i.e. single-word repetitions] that seem to indicate that the speaker is playing for time appear at various kinds of junctures in discourse - between chunk boundaries and clause boundaries, for instance. Thus they occur between elements that are principal message-bearing units and the most crucial contributors to the evolving shared understanding of content. In this way, the repeats, together with hesitations and filled pauses, facilitate processing for both speakers and hearers by dishing out the message in shortish chunks.

(Mauranen, 2012: 230) 
The so-called disfluency features mentioned in the above quote, repeats (as a special form of repetition), hesitations and pauses, along with other such features (e.g., rephrasing), are a normal part of speaking (see Rühlemann, 2007). While they may still be seen as making an individual's speech less fluent, both Mauranen's (2012) research on ELF and studies on L1 and L2 fluency (e.g., Carroll, 2000; Peltonen, 2017; Rühlemann et al., 2011) suggest that they may serve important interactional functions, and contribute to the fluency of the interaction (cf., Hüttner, 2009). For instance, Peltonen (2017) has shown how repetitions may function as fluency enhancing resources in interactions, rather than as markers of disfluency. In other words, what may seem to be a disfluency in an individual speaker's performance may actually benefit the interaction as a whole.

In terms of (self-)rephrasing, Mauranen's (2007) findings show that rephrasings typically concerned form and could thus be seen to work towards clarity and in helping to avoid misunderstandings. According to Mauranen (2007), rephrasings can be seen to increase the chances of being understood by listeners, as it is likely that at least one of the different formulations will get across to them. This is evident in one of Pietikäinen's (2018: 15-16) examples, where a speaker insisted on self-repairing until her interlocutor produced a satisfactory token of understanding (cf., Carroll, 2000). Similar findings are reported, for instance, by Kaur (2009), who concludes that speakers employed rephrasing when the listener was perceived to have difficulty in understanding them. Self-rephrasing may thus serve important interactional functions, even though the need to repair might also be related to the speaker's limited L2 competence.

As a result, it seems that both repetition and rephrasing in ELF serve important interactional or problem-solving functions in that they may increase the chances of mutual understanding. As also suggested in L2 fluency research, they are not straightforward markers of disfluency. The findings reported above can thus be seen to support approaching repair practices (i.e., repetition and rephrasing) in ELF as fluency-enhancing resources (cf., Peltonen, 2017), rather than simply as markers of disfluency in an individual's speech production, as well as considering the phenomenon not only by quantifying the features, but also from the perspective of the functions that the different forms of repair perform in the interaction. In all, the findings seem to be in line with Sato's (2014) suggestion that individual and interactional oral fluency may be two different constructs; that specific fluency features may be perceived differently when they occur in individual performance as opposed to during interaction. This direction is also evident in other L2 fluency studies where fluency is approached as an interactional phenomenon (e.g., Peltonen, 2017; Tavakoli, 2016). 
In addition to repairs (as markers of repair fluency), utterance fluency studies have often focused on the amount and speed of speech (i.e., speed fluency) as well as the number, length and position of pauses (i.e., breakdown fluency) (see Skehan, 2003, 2009; Tavakoli \& Skehan, 2005). The perspective has often been quantitative (however, see Peltonen $\&$ Lintunen, 2016), whereas in ELF studies, these aspects have received limited attention, and rather from a more qualitative perspective where, for instance, functions of the pauses in the interactive creation of meaning have been considered (e.g., Böhringer, 2007).

In L2 fluency studies, a higher speech rate with fewer discontinuities is often seen as an indication of more automatic language processing, and thus an indication of more fluent speech (see Segalowitz, 2010). This understanding is plausible from the perspective of an individual's speech production, but it seems that when the speed of delivery and pauses are considered as an interactional phenomenon, the situation becomes more complex. This interactional perspective has been adopted within some L2 fluency studies; for instance, drawing on his corpus analysis of interactional data, McCarthy (2010: 7) argues that fluency during interaction is a question of "shared responsibility to fill silences and uncomfortably long pauses". This kind of minimising of gaps and overlaps has actually been suggested as a universal feature of conversation (Stivers et al., 2009). Sato (2014) similarly states that while pauses in monologic speech may be an indication of slow L2 processing, in interaction pauses relate to turn-taking and may be a sign of unwillingness to participate. He suggests that in interaction, "pause phenomena could be conceptualized as worse turn-taking or higher levels of engagement, as opposed to the actual speed of producing L2” (Sato, 2014: 86).

In ELF research, the interactional focus has been particularly pronounced, and as discussed above in relation to repair fluency, considerable attention has been paid to how speakers jointly achieve mutual understanding. In terms of speed and breakdown fluency, Deterding's (2013: 173) study on misunderstandings in ELF suggests that fast speech delivery "may have a negative impact on intelligibility and it can give rise to misunderstandings". His conclusion is that participants in ELF interaction are best advised to slow down their speech if they want to increase their chances of being understood. Interestingly, Derwing and Munro's (2001) study on speech rates also shows that listeners preferred a somewhat slower speech rate when the accent of the speaker was other than their own, which tends to be the case in ELF interaction. The fluent speech of an individual - produced with a higher speech rate and fewer discontinuities - may thus not be productive in ELF interaction. Rather, it seems that what is called for is the ability of the speaker to adjust their speech rate and pause behaviour 
according to their interlocutors and the interactional situation, which further highlights the centrality of accommodation in ELF interaction (see Jenkins, 2000).

\section{Perceived fluency in ELF}

In terms of perceived fluency, much L2 fluency research has focused on listener perceptions of an individual speaker's speech production. However, there seems to be no doubt that a speaker may be perceived as more or less fluent depending on the interactional situation and their co-interactants (see e.g., Fillmore, 1979; Tavakoli, 2016). For instance, Sato (2014: 88) concludes that "oral fluency in an individual context is at best weakly indicative of performance in an interactional context", which leads him to distinguish between individual and interactional oral fluency. While individual fluency relates to the speaker's ability to produce fluent speech within their turn, interactional fluency relates to the shared responsibility of the participants to maintain fluency across turns (see McCarthy, 2010; Peltonen, 2017). Distinguishing between these two constructs may actually be key to also understanding the implications of ELF research for studying L2 fluency. As stated at the outset, the focus of ELF research has been on interaction, whereas much of L2 fluency research has dealt with monologic data. ELF research findings can thus shed light on what constitutes fluent conversation, as well as how individual fluency is manifested and perceived in interaction.

What, then, contributes to perceived fluency in an interactional rather than a monologic context? Hüttner (2009) found that the raters in her data did not pay attention to individual speech rate in ELF interactions, which led her to conclude that the speed of delivery may not be a decisive characteristic of fluency in ELF at all. In addition, she conjectures that interactional features such as backchannels and lack of pauses during the interaction possibly contributed to how the raters perceived the fluency of the samples. Similarly, Sato (2014) found that turn-taking, scaffolding and pauses during the interaction influenced how fluent a learner was perceived to be during peer interaction. The findings of these two studies, from ELF and L2 fluency research respectively, thus point in the same direction, namely that the level of co-construction in the interaction is likely to influence perceptions of individual fluency.

One important aspect related to perceived fluency that I have not yet touched upon is the question of who the raters used in evaluating L2 performance are. In L2 fluency studies, the raters tend to be L1 speakers of the target language, which means that the studies yield L1 
speaker perceptions of L2 production, which also seems to be typical of studies that focus on interactional fluency, such as that of Sato (2014). However, from an ELF perspective, sole reliance on L1 raters is problematic because this appears to presume that L1 English speakers are automatically experts of ELF interaction and that L1 use of English is the production target. Quite the contrary, ELF research has shown that achieving mutual understanding requires adaptation on the part of all participants in the interaction - including L1 English speakers (e.g., Jenkins, 2000). ELF research thus questions measuring fluency against a "native speaker" target or using only native speakers as raters. I will return to these issues in more detail below.

To sum up, research on ELF, with its focus on communication, can be seen to encourage the kind of fluency research that has considered how specific interactional features enhance the fluency of the interaction and the fluency of individuals as part of the interaction, that is, research that focuses on interactional oral fluency as a construct distinct from individual oral fluency (e.g., McCarthy, 2010; Peltonen, 2017; Sato, 2014).

\section{Implications of ELF research for studying and assessing $L 2$ fluency}

Based on the above discussion, ELF research seems to highlight three main issues that should be taken into account when approaching L2 fluency, particularly in ELF contexts. Firstly, fluency in ELF should be approached as an interactional phenomenon. In all three of Segalowitz's (2010) dimensions of fluency, the focus is on the individual. In terms of cognitive fluency, attention is paid to speed and effectiveness of speech processing and thus the limitations of an individual's cognitive capacities. Utterance fluency, which, following Skehan's (2003, 2009; Tavakoli \& Skehan, 2005) classification, typically focuses on speed, breakdown and/or repair fluency, tends to be studied either by using monologic data or by considering an individual's speech as distinct from the interactional context. A similar focus on monologic performance is also true of most studies focusing on perceived fluency. However, more interactional perspectives on L2 fluency have also been suggested (McCarthy, 2010; Peltonen, 2017; Sato, 2014), and it is these studies that ELF research comes closest to. Hüttner (2009) goes as far as to say that fluency is a characteristic of the interaction, rather than of individual speakers, but I would suggest drawing on the distinction between the constructs of individual and interactional fluency as presented, for instance, in McCarthy (2010) and Sato (2014). While ELF research, because of its interactional focus, naturally seems to support approaching fluency in interaction, retaining this distinction makes it 
possible to consider not only how fluency is jointly achieved by participants in interaction (e.g., through smooth turn-taking), but also how an individual speaker may be more or less fluent in producing speech in more monologic stretches of language (e.g., by using more or fewer unfilled pauses).

Secondly, fluency in ELF interaction should not be evaluated against an L1 English model, or solely by L1 English speakers. Much fluency research seems to continue using monolingual L1 speech as a model to which L2 production is compared (e.g., Götz, 2013; Peltonen \& Lintunen, 2016; however, see Chambers, 1997; House, 2002). Peltonen and Lintunen (2016) also point out that it is only in recent years that fluency researchers have tended to use an L1 speaker control group. In addition, in studies on perceived fluency, raters have typically been L1 speakers. From an ELF perspective, this sole reliance on L1 models is problematic. ELF interactions take place in situations that are essentially multilingual, and where there may not be any L1 English speakers present. It is therefore clear that using (often monolingual) L1 English speakers (typically from so-called "inner circle" countries, see Kachru, 1996) or interactions between L1 English speakers as a model for ELF interaction makes little sense. It is true that much in ELF resembles ENL (Mauranen, 2012), but at the same time, norms related to ENL interaction may not be important - or may not even be familiar - to the participants in ELF interaction; rather, norms are negotiated without necessarily drawing on L1 norms at all (see Hynninen, 2016). This means that fluency in ELF should be viewed in its own right, without treating ENL interactions as a model, and furthermore, that perceptions of fluency in ELF interaction by L2 users are just as relevant, if not more relevant, than the perceptions of L1 speakers.

Thirdly, following from the discussion above, the construct of interactional fluency should be taken seriously in assessing L2 speech production. In addition, in order to cater for contextual factors, the construct should be developed by drawing on research on various kinds of interactions, including those conducted in ELF. It is striking that the Common European Framework of Reference for Languages (CEFR, 2001), for instance, seems to treat fluency very much as a characteristic of individual speech production. This is illustrated by the following extract from the descriptor for fluency at level B2:

Can produce stretches of language with a fairly even tempo; although he/she can be hesitant as he/she searches for patterns and expressions, there are few noticeably long pauses. 
Fluency in the CEFR evidently seems to relate to speed, pausing and repair (see Skehan, 2003; 2009) in an individual speaker's production. Within SLA research, however, it has been suggested more generally that interactional aspects should be taken into account in assessment. For example, Lindemann's (2006) study on L1-L2 interactions revealed that the L2 speakers' performance in the interaction was influenced by the interactional behaviour of the L1 speaker (which in turn was influenced by speaker attitudes). Based on these findings, Lindemann (2006) argues that L2 speaker performance can be assessed in relation to what the listener does, since as she puts it, "[i]t takes (at least) two to converse" (Lindemann, 2006: 24). In a similar vein, Bavelas et al. (2000), who studied the role of the listener in the speaker's storytelling, argue that the relationship between speaker and listener is reciprocal and collaborative. Their findings show that "the narrator elicits responses from the listener and the listener's responses affect the narrator" (Bavelas et al. 2000: 951). Hence, the particular challenge for assessing L2 fluency seems to be that an individual speaker may appear more or less fluent depending on their co-interactant. This raises the question of the kind of fluency that the assessment should focus on: Should individual fluency be assessed in an interactional context or rather in monologic production only? Furthermore, if the focus is on interactional fluency, how can we incorporate a proficiency dimension into it, that is, distinguish between speakers who contribute to interactional fluency more than others?

\section{Some open questions}

It was established above that ELF research suggests that fluency can be viewed as an interactional phenomenon, with the focus on the kind of language use that contributes to interactional fluency. The question which then arises is, what contributes to interactional fluency, namely what do speakers do to achieve it? Moreover, how do we distinguish, if indeed it is possible to do so (cf., Hüttner, 2009), between speakers who contribute to interactional fluency more than others? In what ways are these speakers fluent, or is it even possible to establish a connection between interactional fluency and the fluency of individual speakers taking part in the interaction?

ELF interaction has been found to require adaptation on the part of all participants (e.g., Jenkins, 2000). This observation raises the question of whether fluency is related to the flexibility of the participants to adapt their language and attune their ears according to the situation and their co-participants. Not much has been said about the issue in relation to 
fluency, but based on the discussion above it would appear that acting like this, combined with doing pre-emptive work to avoid non- and misunderstandings (e.g., Pietikäinen, 2018), for example, seems to move the interaction along. This in turn may be an indication of increased interactional fluency, resulting, for instance, in fewer or shorter pauses during interaction (see McCarthy, 2010). If this is true, a speaker who, say, self-repairs could be taking responsibility for the interaction and contributing to interactional fluency - even if the self-repairs may (or may not) be seen to decrease the speaker's individual fluency. In any case, there is a need to investigate further what kind of language use contributes to interactional fluency in ELF (and otherwise), and in what ways features associated with individual (dis)fluency may actually serve specific functions in interaction.

When it comes to who is likely to contribute to interactional fluency more than others, we may turn our attention to speakers who possess the capacity to function as an intermediary between speakers who, for whatever reason, do not seem to understand each other, or who run the risk of misunderstanding each other (see Hynninen, 2012; 2016). Interestingly, this intermediary role is also acknowledged in the CEFR Companion Volume (2018: 33-34; see also CEFR, 2001) where mediation is highlighted as one of the four communicative language strategies (the others being reception, production and interaction). The fact that intermediaries intervene in interaction is likely to reduce gaps in turn-taking, and thus the act itself can be seen to contribute to interactional fluency. Furthermore, the way intermediaries behave (e.g., by rephrasing a previous speaker's expression) can shed light on the interactional functions of specific (dis)fluency features, such as repetitions and rephrasings.

\section{Conclusion}

What this review of ELF research suggests is that both L2 fluency research and L2 assessment pay more attention to interaction and to how individuals' contributions are tied to the interactional situations in which they are communicating. Clearly, more work needs to be done to better understand the relationship between individual and interactional fluency, and the way in which the two constructs can be used when evaluating speaker performance in ELF interaction. In terms of assessing English, a further challenge is to empirically investigate what exactly constitutes fluent communication in ELF - and who can determine that. What kind of ELF interaction is perceived as fluent? Which features are typical of such interaction, and what do speakers do in such interaction? The aim of this review has been to provide some initial observations and a starting point for further research on these issues. 


\section{References}

Bavelas, J., Coates, L. and Johnson, T. (2000) Listeners as co-narrators. Journal of Personality and Social Psychology 79 (6), 941-952.

Böhringer, H. (2007) The sound of silence: Silent and filled pauses in English as a lingua franca business interaction. MA thesis, University of Vienna.

Bosker, H. R., Pinget, A.-F., Quené, H., Sanders, T. and De Jong, N. H. (2013) What makes speech sound fluent? The contributions of pauses, speed and repairs. Language Testing $30,159-175$.

Carroll, D. (2000) Precision timing in novice-to-novice L2 conversations. Issues in Applied Linguistics 11 (1), 67-110.

CEFR (2001) Common European Framework of Reference for Languages: Learning, Teaching, Assessment. Council of Europe. Available online at: https://rm.coe.int/1680459f97.

CEFR Companion volume (2018) Common European Framework of Reference for Languages: Learning, Teaching, Assessment. Companion Volume with New Descriptors. Council of Europe. Available online at: https://rm.coe.int/cefr-companionvolume-with-new-descriptors-2018/1680787989.

Chambers, F. (1997) What do we mean by fluency? System 25 (4), 535-44.

Cogo, A. and Dewey, M. (2006) Efficiency in ELF communication: From pragmatic motives to lexico-grammatical innovation. Nordic Journal of English Studies 5 (2), 59-93.

Derwing, T. and Munro, M. (2001) What speaking rates do nonnative listeners prefer? Applied Linguistics 22 (3), 324-337.

Deterding, D. (2013) Misunderstandings in English as a Lingua Franca. An Analysis of ELF Interactions in South-East Asia. Berlin: De Gruyter Mouton.

Fillmore, C. J. (1979) [2000] On fluency. In H. Riggenbach (ed.) Perspectives on Fluency (pp. 43-60). Ann Arbor, MI: University of Michigan Press.

Firth, A. (1996) The discursive accomplishment of normality: On "lingua franca" English and conversation analysis. Journal of Pragmatics 26 (2), 237-259.

Götz, S. (2013) Fluency in Native and Nonnative English Speech. Amsterdam: John Benjamins. 
House, J. (1999) Misunderstanding in intercultural communication: Interactions in English as lingua franca and the myth of mutual intelligibility. In C. Gnutzmann (ed.) Teaching and Learning English as a Global Language (pp. 73-89). Tübingen: Strauffenburg.

House, J. (2002) Developing pragmatic competence in English as a lingua franca. In K. Knapp and C. Meierkord (eds) Lingua Franca Communication (pp. 245-268). Frankfurt am Main: Peter Lang.

Hüttner, J. (2009) Fluent speakers - fluent interactions: On the creation of (co)-fluency in English as a lingua franca. In A. Mauranen and E. Ranta (eds) English as a Lingua Franca: Studies and Findings (pp. 274-297). Newcastle upon Tyne: Cambridge Scholars Publishing.

Hynninen, N. (2012) ICL at the micro level: L2 speakers taking on the role of language experts. AILA Review 25, 13-29.

Hynninen, N. (2016) Language Regulation in English as a Lingua Franca: Focus on Academic Spoken Discourse. Berlin: De Gruyter Mouton.

Jenkins, J. (2000) The Phonology of English as an International Language. Oxford: Oxford University Press.

Jenkins, J. (2007) English as a Lingua Franca: Attitude and Identity. Oxford: Oxford University Press.

Kachru, B. B. (1996) Opening borders with world Englishes: Theory in the classroom. In S. Cornwell, P. Rule and T. Sugino (eds), On JALT96: Crossing Borders. The Proceedings of the 23rd Annual JALT International Conference on Language Teaching/learning, Hiroshima, Japan, November 1996 (pp. 10-20). JALT, Tokyo.

Kaur, J. (2009) Pre-empting problems of understanding in English as a lingua franca. In A. Mauranen and E. Ranta (eds) English as a Lingua Franca: Studies and Findings (pp. 107-123). Newcastle upon Tyne: Cambridge Scholars Publishing.

Kaur, J. (2011) Raising explicitness through self-repair in English as a lingua franca. Journal of Pragmatics 43 (11), 2704-2715.

Kormos, J. and Dénes, M. (2004) Exploring measures and perceptions of fluency in the speech of second language learners. System 32, 145-164.

Lindemann, S. (2006) What the other half gives: The interlocutor's role in non-native speaker performance. In R. Hughes (ed.) Spoken English, TESOL and Applied Linguistics: Challenges for Theory and Practice (pp. 23-49). Basingstoke: Palgrave Macmillan.

Mauranen, A. (2006) Signaling and preventing misunderstanding in English as lingua franca communication. International Journal of the Sociology of Language 177, 123-150. 
Mauranen, A. (2007) Hybrid voices: English as the lingua franca of academics. In K. Fløttum (ed.), Language and Discipline Perspectives on Academic Discourse (pp. 243-259). Newcastle upon Tyne: Cambridge Scholars Publishing.

Mauranen, A. (2012) Exploring ELF. Academic English Shaped by Non-native Speakers. Cambridge: Cambridge University Press.

Mauranen, A. (2017) Conceptualising ELF. In J. Jenkins, W. Baker and M. Dewey (eds) The Routledge Handbook of English as a Lingua Franca (pp. 7-24). London: Routledge.

McCarthy, M. (2010) Spoken fluency revisited. English Profile Journal 1 (1), 1-15.

Pawley, A. and Syder, F. H. (1983) Two puzzles for linguistic theory: Nativelike selection and nativelike fluency. In J. C. Richards and R. W. Schmidt (eds) Language and communication (pp. 191-225). London: Longman.

Peltonen, P. (2017) Temporal fluency and problem-solving in interaction: An exploratory study of fluency resources in L2 dialogue. System 70, 1-13.

Peltonen, P. and Lintunen, P. (2016) Integrating quantitative and qualitative approaches in L2 fluency analysis: A study of Finnish-speaking and Swedish-speaking learners of English at two school levels. European Journal of Applied Linguistics 4 (2), 209-238.

Pietikäinen, K. S. (2018) Misunderstandings and ensuring understanding in private ELF talk. Applied Linguistics 39 (2), 188-212.

Pitzl, M.-L. (2012) Creativity meets convention: Idiom variation and re-metaphorization in ELF. Journal of English as a Lingua Franca 1 (1), 27-55.

Prodromou, L. (2008) English as a Lingua Franca. A Corpus-Based Analysis. London: Continuum.

Ranta, E. (2009) Syntactic features in spoken ELF - Learner language or spoken grammar? In A. Mauranen and E. Ranta (eds) English as a Lingua Franca: Studies and Findings (pp. 84-106). Newcastle upon Tyne: Cambridge Scholars Publishing.

Riggenbach, H. (1991) Toward an understanding of fluency: A microanalysis of nonnative speaker conversations. Discourse Processes 14, 423-441.

Rühlemann, C. (2007) Conversation in Context: A Corpus-driven Approach. London: Continuum.

Rühlemann, C., Bagoutdinov, A. and O'Donnell, M. B. (2011) Windows on the mind: Pauses in conversational narrative. International Journal of Corpus Linguistics 16 (2), 198-230.

Sato, M. (2014) Exploring the construct of interactional oral fluency: Second Language Acquisition and Language Testing approaches. System 45, 79-91.

Segalowitz, N. (2010) Cognitive Bases of Second Language Fluency. London: Routledge. 
Seidlhofer, B. (2004) Research perspectives on teaching English as a lingua franca. Annual Review of Applied Linguistics 24, 209-239.

Seidlhofer, B. (2011) Understanding English as a Lingua Franca. Oxford: Oxford University Press.

Seidlhofer, B. and Widdowson, H. (2009) Conformity and creativity in ELF and learner English. In M. Albl-Mikasa, S. Braun and S. Kalina (eds) Dimensionen der Zweitsprachenforschung. Dimensions of Second Language Research. (Festschrift for Kurt Kohn) (pp. 93-107). Tübingen: Narr.

Simpson, R. C., Briggs, S. L., Ovens, J. and Swales, J. M. (2002) The Michigan Corpus of Academic Spoken English. Ann Arbor, MI: The Regents of the University of Michigan.

Skehan, P. (2003) Task-based instruction. Language Teaching 36 (1), 1-14.

Skehan, P. (2009) Modelling second language performance: Integrating complexity, accuracy, fluency, and lexis. Applied Linguistics 30 (4), 510-532.

Stivers, T., Enfield, N. J., Brown, P., Englert, C., Hayashi, M., Heinemann, T., Hoymanna, G., Rossano, F., de Ruiter, J. P., Yoon, K.-E. and Levinson, S. C. (2009) Universals and cultural variation in turn-taking in conversation. PNAS (Proceedings of the National Academy of Sciences) 106 (26), 10587-10592.

Tavakoli, P. (2016) Fluency in monologic and dialogic task performance: Challenges in defining and measuring L2 fluency. International Review of Applied Linguistics in Language Teaching 54, 133-150.

Tavakoli, P. and Skehan, P. (2005) Strategic planning, task structure, and performance testing. In R. Ellis (ed) Planning and Task Performance in a Second Language (pp. 239-273). Amsterdam \& Philadelphia: John Benjamins.

Vetchinnikova, S. (2014) Second language lexis and the idiom principle. $\mathrm{PhD}$ thesis, University of Helsinki.

Wray, A. (2002) Formulaic Language and the Lexicon. Cambridge: Cambridge University Press. 